\title{
Role of Counterregulatory Hormones in the Catabolic Response to Stress
}

\author{
Robert A. Gelfand, Dwight E. Matthews, Dennis M. Bier, \\ and Robert S. Sherwin \\ Department of Internal Medicine and the General Clinical \\ Research Center, Yale University School of Medicine, New \\ Haven, Connecticut 06510; Departments of Medicine and \\ Pediatrics, Washington University School of Medicine, \\ St. Louis, Missouri 63110
}

bstract. Patients with major injury or illness develop protein wasting, hypermetabolism, and hyperglycemia with increased glucose flux. To assess the role of elevated counterregulatory hormones in this response, we simultaneously infused cortisol $\left(6 \mathrm{mg} / \mathrm{m}^{2}\right.$ per $\left.\mathrm{h}\right)$, glucagon $(4 \mathrm{ng} / \mathrm{kg}$ per $\mathrm{min})$, epinephrine $\left(0.6 \mu \mathrm{g} / \mathrm{m}^{2}\right.$ per $\mathrm{min})$, and norepinephrine $\left(0.8 \mu \mathrm{g} / \mathrm{m}^{2}\right.$ per $\left.\mathrm{min}\right)$ for $72 \mathrm{~h}$ into five obese subjects receiving only intravenous glucose $(150 \mathrm{~g} / \mathrm{d})$. Four obese subjects received cortisol alone under identical conditions.

Combined infusion maintained plasma hormone elevations typical of severe stress for $3 \mathrm{~d}$. This caused a sustained increase in plasma glucose $(60-80 \%)$, glucose production (100\%), and total glucose flux (40\%), despite persistent hyperinsulinemia. In contrast, resting metabolic rate changed little ( $9 \%$ rise, $P=\mathrm{NS}$ ). Urinary nitrogen excretion promptly doubled and remained increased by $\sim 4 \mathrm{~g} / \mathrm{d}$, reflecting increased excretion of urea and ammonia. Virtually all plasma amino acids declined. The increment in nitrogen excretion was similar in three additional combined infusion studies performed in 3-d fasted subjects not receiving glucose.

Cortisol alone produced a smaller glycemic response (20-25\%), an initially smaller insulin response, and a delayed rise in nitrogen excretion. By day 3 , however, daily nitrogen excretion was equal to the combined

This work was presented in part at the National Meeting of the American Federation for Clinical Research, Washington, DC, April 1983.

Address reprint requests to Dr. Gelfand, Yale University School of Medicine, Box 3333, Fitkin I, New Haven, CT 06510.

Received for publication 6 February 1984 and in revised form 2 August 1984.

J. Clin. Invest.

(C) The American Society for Clinical Investigation, Inc. $0021-9738 / 84 / 12 / 2238 / 11 \quad \$ 1.00$

Volume 74, December 1984, 2238-2248 group as was the elevation in plasma insulin. Most plasma amino acids rose rather than fell. In both infusion protocols nitrogen wasting was accompanied by only modest increments in 3-methylhistidine excretion ( $\sim 20$ $30 \%$ ) and no significant change in leucine flux.

We conclude: (a) Prolonged elevations of multiple stress hormones cause persistent hyperglycemia, increased glucose turnover, and increased nitrogen loss; $(b)$ The sustained nitrogen loss is no greater than that produced by cortisol alone; (c) Glucagon, epinephrine, and norepinephrine transiently augment cortisol-induced nitrogen loss and persistently accentuate hyperglycemia; $(d)$ Counterregulatory hormones contribute to, but are probably not the sole mediators of the massive nitrogen loss, muscle proteolysis, and hypermetabolism seen in some clinical settings of severe stress.

\section{Introduction}

The response to major injury or illness is characterized by profound alterations in body protein economy and fuel metabolism $(1,2)$. The hallmarks of this response include an accelerated loss of body protein, hypermetabolism, and hyperglycemia with increased glucose turnover (3-5). This catabolic picture contrasts sharply with the fall in metabolic rate, preservation of body protein, and reduction in glucose flux observed with simple starvation (6).

The regulatory mechanisms initiating and maintaining the catabolic response to stress have not been clearly established. Particular interest has focused on the characteristic neuroendocrine alterations associated with stressful clinical states. Patients with trauma, burns, or sepsis regularly exhibit pronounced elevations in circulating plasma levels of the counterregulatory, or "anti-insulin" hormones, cortisol $(5,7-9)$, glucagon (6, 7-9), and catecholamines $(5,9,10)$. Although it has long been postulated that these hormonal changes may account for the metabolic derangements observed during stress, direct experimental support for this hypothesis is sparse. Previous studies have suggested that cortisol $(11,12)$ and glucagon $(13$, 
14) may be important in stress-induced nitrogen wasting, catecholamines in the thermic response (15), and multiple hormones in the altered glucose metabolism $(16,17)$. However, no study has directly examined whether the combined elevations of counterregulatory hormones that regularly accompany serious illness can in fact fully account for the metabolic alterations observed clinically in this setting.

In this study we administered infusions of counterregulatory hormones for $72 \mathrm{~h}$ into healthy, unstressed individuals to further examine the relationship between the hormonal milieu of stress and the various facets of the catabolic response.

\section{Methods}

Subjects and experimental protocol. Nine healthy obese subjects (seven females and two males), aged 21-32 yr, weighing 32-83\% (55 $\pm 7 \%$, mean \pm SEM) above ideal body weight (Metropolitan Life Insurance Tables, 1959), were admitted to the Clinical Research Center of YaleNew Haven Hospital for 2 wk. All had normal fasting plasma glucose levels $(<105 \mathrm{mg} / \mathrm{dl})$, and normal thyroid, renal, and liver function tests. None had a history of heart disease, and all had normal electrocardiograms and were normotensive. None were taking any medications. All were consuming weight-maintaining diets prior to study.

After admission to the Yale Clinical Research Center, study participants' total caloric intake was restricted to $150 \mathrm{~g}$ of carbohydrate daily and remained fixed at this level for the duration of the study. For an initial 6-7-d stabilization period, this was provided in the form of an essentially pure carbohydrate diet (e.g., fruit juice, popsicles, etc.). This prestudy diet period was designed to allow daily urinary nitrogen excretion to reach a relatively stable plateau ( $<10 \%$ decline/d); this, in turn, facilitated interpretation of the subsequent response to hormone infusion. Following the week of stabilization with oral carbohydrates, subjects were switched to intravenous glucose $(150 \mathrm{~g} / \mathrm{d}$ by continuous infusion), which constituted their sole caloric intake throughout the experimental period. Metabolic measurements and hormone infusions were thus performed under conditions resembling the dextrose-inwater feeding regimen routinely administered to hospitalized patients. Individuals maintained a daily fluid intake of at least 2 liter, and received daily oral supplements of multivitamins (Rowell Laboratories, Baudette, MN), folic acid (1 mg, Folvite, Lederle Laboratories, Pearl River, NY), and $\mathrm{KCl}(20 \mathrm{meq})$

The hormone infusion period began on the morning of the third day of intravenous glucose. Subjects received continuous infusions of counterregulatory hormones for $72 \mathrm{~h}$ beginning at $0900 \mathrm{~h}$. Five subjects (four females and one male) received simultaneous infusions of cortisol $\left(6 \mathrm{mg} / \mathrm{m}^{2}\right.$ per $\mathrm{h}$ ), glucagon $(4 \mathrm{ng} / \mathrm{kg}$ per $\mathrm{min})$, epinephrine $\left(0.6 \mu \mathrm{g} / \mathrm{m}^{2}\right.$ per $\mathrm{min})$, and norepinephrine $\left(0.8 \mu \mathrm{g} / \mathrm{m}^{2}\right.$ per $\left.\mathrm{min}\right)$. The doses used were known from previous studies to produce plasma hormone elevations characteristic of severe stress (17). Four participants (three females and one male) received a 72-h infusion of cortisol alone. Infusates were freshly prepared every 6-12 h. Epinephrine (adrenalin chloride, Parke-Davis Co., Morris Plains, NJ) and norepinephrine (levophed bitartrate, Breon Laboratories, New York) were prepared in sterile saline to which ascorbic acid (Cevalin, Eli Lilly and Co., Indianapolis, IN) was added to retard oxidation $(1 \mathrm{mg} / \mathrm{ml})$. Hydrocortisone sodium succinate (Solucortef, Upjohn Co., Kalamazoo, MI) was added to the subjects' dextrose-in-water infusions. Crystalline glucagon (Eli Lilly and Co.) was prepared in a solution of isotonic saline containing human serum albumin $(300 \mathrm{mg} / \mathrm{dl})$. Infusions were administered via portable Abbott infusion pumps (Abbott Laboratories, North Chicago, IL), which allowed subjects relative freedom of movement. A physician was present at all times throughout the infusion period.

Blood and urine sampling was begun $24 \mathrm{~h}$ before initiation of the hormone infusions. Venous blood samples were obtained daily at 0800,1200 , and $1600 \mathrm{~h}$ for $5 \mathrm{~d}$; daily values for each subject were derived from the mean of the determinations over a given 24-h period. 24-h urine collections were obtained daily starting at 0900; all urine was refrigerated immediately after voiding, and aliquots of each 24-h collection were stored at $-20^{\circ} \mathrm{C}$ before analysis.

On the morning of the day prior to hormone infusion, and again on the morning of the third infusion day, kinetic studies of glucose turnover and leucine metabolism were performed together with analysis of respiratory gas exchange by indirect calorimetry. For these studies venous catheters were inserted in each arm for isotope administration and for blood sampling. Glucose turnover was measured using a primed-continuous infusion of $\left[3-{ }^{3} \mathrm{H}\right]$ glucose (New England Nuclear, Boston, MA). A primary dose of $35 \mu \mathrm{Ci}$ was followed by a constant infusion of $0.25 \mu \mathrm{Ci} / \mathrm{min}$ for $3 \mathrm{~h}$. Plasma samples for glucose concentration and $\left[3-{ }^{3} \mathrm{H}\right]$ glucose specific activity were obtained at 15 -min intervals during the last hour of infusion, by which time a stable plateau of specific activity had been reached in all subjects. Measurement of leucine metabolism was simultaneously performed using a primedcontinuous infusion of $\mathrm{L}-\left[1-{ }^{13} \mathrm{C}\right]$ leucine. This technique has been described in detail previously $(18) . \mathrm{L}-\left[1-{ }^{13} \mathrm{C}\right]$ leucine $\left(92 \%{ }^{13} \mathrm{C}\right)$ and sodium $\left[{ }^{13} \mathrm{C}\right]$ bicarbonate $\left(90 \%{ }^{13} \mathrm{C}\right.$ ) (KOR Isotopes, Cambridge, MA) were administered in priming doses of 10.4 and $4.4 \mathrm{mg} / \mathrm{m}^{2}$, respectively, followed by a constant infusion of $\mathrm{L}-\left[1-{ }^{13} \mathrm{C}\right]$ leucine at $12.4 \mathrm{mg} / \mathrm{m}^{2}$ per h for $240 \mathrm{~min}$. Blood samples and expired air were obtained just before administration of isotope and at 15 -min intervals during the last $90 \mathrm{~min}$ of infusion. Isotope enrichment (atom percent excess) reached a stable plateau in both plasma leucine and expired $\mathrm{CO}_{2}$ in all subjects within 150-165 min. Respiratory gas was measured for 60-90 min during isotope infusion using the ventilated hood technique (19).

Finally, to determine whether the concurrent glucose infusion and prolonged caloric deprivation substantially influenced the effects of the hormones on nitrogen balance, three additional obese individuals were studied under conditions of short-term total fasting. The participants fasted for $3 \mathrm{~d}$ prior to a 48 -h combined counterregulatory hormone infusion, given without intravenous glucose. Fluid intake and vitamin and mineral supplementation were as described above. The subjects' clinical characteristics were comparable with those studied under the previous protocol, with regard to age (25-39 yr), weight (27-62\% above ideal body weight), and sex distribution (two female and one male). The hormone doses and the schedule of daily blood and urine sampling was the same as used in the glucose-infused subjects.

All subjects gave written, informed consent before their participation in the study. The experimental protocol was approved by the Human Investigations Committee of Yale University School of Medicine.

Analyses and calculations. Plasma glucose concentration was measured by the glucose oxidase method using a Beckman glucose analyzer (Beckman Instruments, Inc., Fullerton, CA). Plasma epinephrine and norepinephrine were measured by a radioenzymatic technique (20), and plasma cortisol was determined fluorimetrically (21). The methods used for determination of plasma immunoreactive insulin, plasma immunoreactive glucagon (using Unger antibody $30 \mathrm{~K}$ ), and plasma $\left[3-{ }^{3} \mathrm{H}\right]$ glucose specific activity have been previously described (22). 
Plasma acidic and neutral amino acids and urine 3-methylhistidine were measured using an automated ion-exchange chromatographic technique (Dionex Corp., Sunnyvale, CA). The ${ }^{13} \mathrm{C}$-enrichment in plasma leucine and expired $\mathrm{CO}_{2}$ were determined by mass spectrometry as described previously (18). Plasma free fatty acids were measured colorimetrically (23), and whole blood beta hydroxybutyrate enzymatically (24). Serum triiodothyronine $\left(T_{3}\right)^{1}$ was measured by solid-phase radioimmunoassay (Corning Medical and Scientific, Medfield, MA). Total nitrogen in urine was measured by the standard Kjeldahl technique; urinary urea was determined enzymatically, and ammonia colorimetrically, by routine biochemical methods in the Yale-New Haven Hospital Clinical Chemistry Laboratory. Respiratory gas exchange was measured by the ventilated hood technique, using a constant volume blower and massic air flowmeter (American Meter Division), interfaced with an infrared $\mathrm{CO}_{2}$ analyzer and thermomagnetic $\mathrm{O}_{2}$ analyzer (Applied Electrochemistry Inc., Sunnyvale, CA).

Glucose turnover was calculated by the isotope dilution equation: $R a=R d=F / S A$, where $R a$ is the rate of glucose appearance, $R d$ is the rate of overall glucose disposal, $F$ is the rate of tracer infusion, and $S A$ is glucose specific activity at equilibrium. Endogenous glucose production was determined by subtracting the exogenous glucose infusion rate from the calculated total $R a$.

Whole body leucine flux and oxidation were calculated as described in detail previously (18). Briefly, when isotopic steady state is reached, leucine turnover, or flux $(Q)$, is given by the equation:

$Q=i(E i / E p-1)$

where $i$ is the $\left[1{ }^{13} \mathrm{C}\right]$ leucine infusion rate (millimoles per hour); $E i$, the enrichment of the $\left[1-{ }^{13} \mathrm{C}\right]$ leucine infused (atom percent excess); and $E p$, the $\left[1-{ }^{13} C\right] l e u c i n e$ enrichment in plasma at isotopic plateau (atom percent excess). The rate of leucine oxidation $(C)$, in turn, is given by the equation:

$C=F^{13} \mathrm{CO}_{2}(1 / E p-1 / E i) \times 100$,

where $F^{13} \mathrm{CO}_{2}$ is the rate of ${ }^{13} \mathrm{CO}_{2}$ production (millimoles per hour) from leucine tracer oxidation. Expired gas measurements were corrected by assuming $19 \%$ retention of ${ }^{13} \mathrm{CO}_{2}$ in the body bicarbonate pool (18).

Statistical analyses were performed using Student's $t$ test (the paired $t$ test was used where applicable). A one-way analysis of variance with repeated measures design was also used to compare changes from base line. Data in the text and figures are presented as mean \pm SE.

\section{Results}

\section{Combined counterregulatory hormone infusion}

Circulating hormone concentrations. Fig. 1 shows the effect of the 72-h combined hormone infusion on plasma counterregulatory hormone levels. Cortisol, glucagon, and norepinephrine levels rose three- to fivefold, and epinephrine more than 20fold ( $P<0.05-0.001$ for each hormone, each infusion day). Mean concentrations during the 3-d hormone infusion averaged, for cortisol, $42 \pm 3 \mu \mathrm{g} / \mathrm{dl}$; glucagon, $354 \pm 51 \mathrm{pg} / \mathrm{ml}$; epinephrine, $388 \pm 62 \mathrm{pg} / \mathrm{ml}$; and norepinephrine, $692 \pm 97 \mathrm{pg} / \mathrm{ml}$. When the infusions were discontinued, each hormone promptly returned to control levels.

\footnotetext{
1. Abbreviation used in this paper: $\mathrm{T}_{3}$, triiodothyronine.
}

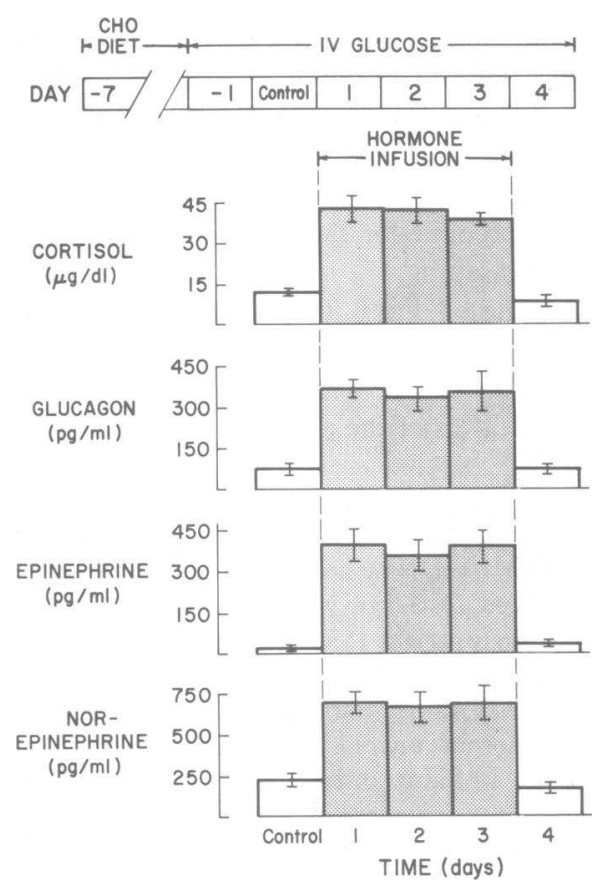

Figure 1. Effect of 72-h combined counterregulatory hormone infusion on circulating counterregulatory hormone levels.

Plasma glucose and insulin, and glucose kinetics (Fig. 2). Plasma glucose concentration $(101 \pm 2 \mathrm{mg} / \mathrm{dl}$, base-line period) rose promptly in response to combined hormone infusion. Hyperglycemia was most marked on the first day (184 $\pm 6, P$ $<0.01)$, but was sustained thereafter $(169 \pm 7$, and $158 \pm 3$ on days 2 and 3 , respectively, $P<0.001$ vs. base line). Modest glycosuria occurred in all subjects; mean $24 \mathrm{~h}$ urine glucose loss ranged from $11.5 \pm 2.8 \mathrm{~g}$ (day 3) to $15.1 \pm 6.6 \mathrm{~g}$ (day 1 ). Circulating insulin levels $(21 \pm 1 \mu \mathrm{U} / \mathrm{ml}$, base line) rose threeto fourfold during hormone infusion $(P<0.01)$, and tended to parallel the change in plasma glucose concentration. Despite significant hyperglycemia $(156 \pm 3 \mathrm{mg} / \mathrm{dl}, P<0.001)$ and hyperinsulinemia $(68 \pm 7 \mu \mathrm{U} / \mathrm{ml}, P<0.001)$, the rate of endogenous glucose production on day 3 was more than double that observed during the control period $(54 \pm 6$ vs. $24 \pm 5 \mathrm{mg} / \mathrm{m}$ per min, $P<0.01$ ). Total body glucose turnover (endogenous production + exogenous infusion) was increased by $40 \%$ ( $P$ $<0.01$ ). Since urinary glucose loss accounted for only $5 \%$ of total turnover, the increase in flux largely reflected augmented tissue uptake of glucose $(32 \%, P<0.01)$.

Urinary total nitrogen, urea, and ammonia excretion (Fig. 3). Net loss of body protein, as reflected by daily total nitrogen excretion, was accelerated by combined hormone elevation. Total nitrogen excretion rose promptly on the first infusion day (from $4.3 \pm 0.7$ to $8.3 \pm 1.0 \mathrm{~g} / 24 \mathrm{~h}, P<0.01$ ) and remained increased thereafter $(8.6 \pm 1.2$ on day 2 , and $8.3 \pm 1.0 \mathrm{~g} / 24 \mathrm{~h}$ on day $3, P<0.01-0.001)$. When the infusions were discontinued, nitrogen excretion returned to baseline levels. Underlying the 


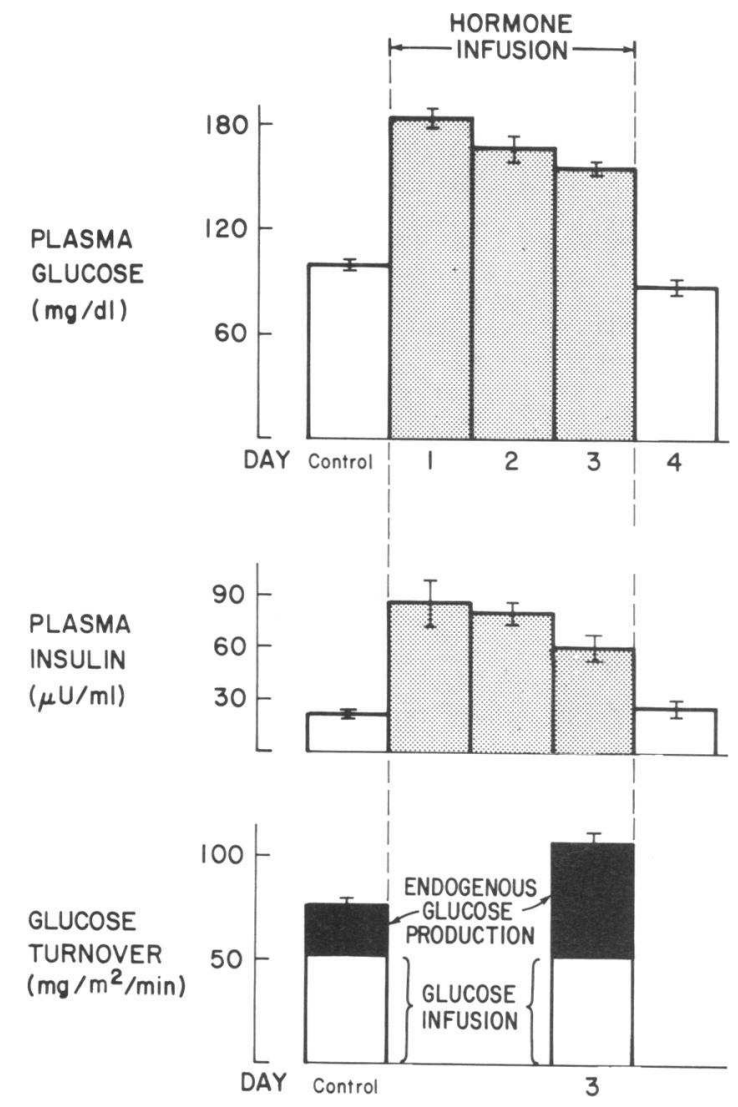

Figure 2. Effect of combined hormone infusion on plasma glucose, insulin, and glucose turnover.

increased total nitrogen loss were significant increments in urea and ammonia excretion (Fig. 3). Urinary urea nitrogen rose nearly twofold (from $2.4 \pm 0.6$ to $4.6 \pm 0.4,4.3 \pm 0.6$, and $3.9 \pm 0.5 \mathrm{~g} / 24 \mathrm{~h}$ on infusion days 1,2 , and 3 , respectively; $P$ $<0.05-0.01)$. Serum urea nitrogen was unchanged throughout $(4 \pm 1$, base line, and $4 \pm 1 \mathrm{mg} / \mathrm{dl}$ on day 3 ), indicating a true increase in urea production rate. Urinary ammonia excretion rose progressively from $0.48 \pm 0.06$ (base line) to $1.62 \pm 0.09 \mathrm{~g} /$ $24 \mathrm{~h}$ (day $3, P<0.001$ ).

Plasma amino acids (Table I). Combined hormone infusion produced a marked decline in plasma amino acids. The total amino acid concentration was significantly reduced on each infusion day (by 41,44 , and $31 \%$ on days 1,2 , and 3 , respectively), reflecting significant decrements in virtually all individual amino acids measured. The greatest declines occurred in the glucogenic amino acids alanine (52\%), threonine (69\%), serine $(58 \%)$, and glycine $(58 \%)$. The branched chain amino acids exhibited a more modest $23-43 \%$ reduction. After the hormone infusion was stopped, the branched chain and most other amino acids returned to base line.

3-Methylhistidine excretion and $\left[1-{ }^{13} \mathrm{C}\right]$ leucine metabolism (Table II). Urinary excretion of 3-methylhistidine tended to increase during the combined infusion, reaching values on day

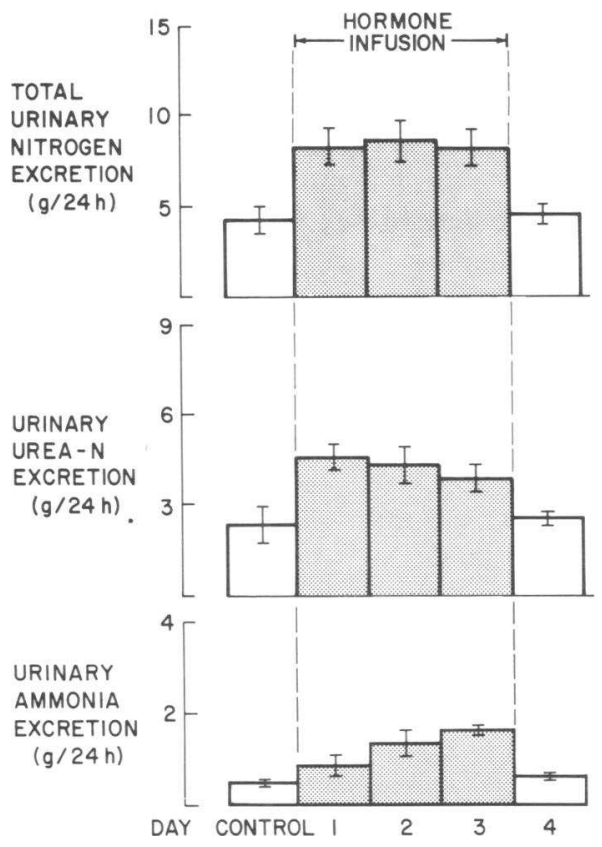

Figure 3. Effect of combined hormone infusion on daily urinary excretion of total nitrogen, urea, and ammonia.

3 that were $34 \%$ greater than base line. However, this response showed considerable intersubject variability, and did not achieve statistical significance $(F=2.89,0.05<P<0.10)$. Neither the flux nor the rate of oxidation of leucine were significantly different on infusion day 3 as compared to base line. However, since plasma leucine fell from $75 \pm 9$ to $56 \pm 8 \mu \mathrm{M}(P<0.01)$, the ratio of whole body leucine turnover to plasma leucine concentration (clearance) rose.

Energy expenditure, $T_{3}$, and lipid metabolites. Resting metabolic rate was measured in four subjects before hormone infusion and again on the third infusion day. A modest $9 \%$ rise in resting metabolic rate was observed $(689 \pm 79$ to $752 \pm 86$ $\mathrm{kcal} / \mathrm{m}^{2}$ per d) that did not achieve statistical significance. Resting pulse rate did not change $(73 \pm 4$, base line, vs. $71 \pm 3$ / min on day 3). $T_{3}$ levels $(124 \pm 13 \mathrm{ng} / \mathrm{ml}$, base line) fell by $27 \%$ during the $72-\mathrm{h}$ infusion (to $90 \pm 7, P<0.05$ ). Neither plasma free fatty acids ( $723 \pm 77 \mu \mathrm{M}$, base line) nor blood beta hydroxybutyrate $(0.12 \pm 0.02 \mathrm{mM}$, base line) showed significant changes during the hormone infusion $(745 \pm 84 \mu \mathrm{M}$ and $0.11 \pm 0.03 \mathrm{mM}$, respectively, day 3 ).

\section{Cortisol alone}

Circulating cortisol, glucose, and insulin. Infusion of cortisol alone produced a sustained rise in plasma cortisol (to $36 \pm 3$ $\mu \mathrm{g} / \mathrm{dl}$ ) that was not significantly different from that achieved with combined hormone infusion. Levels of other counterregulatory hormones remained unchanged. As shown in Fig. 4, the rise in plasma glucose during cortisol infusion $(20-25 \mathrm{mg} / \mathrm{dl}$, $P<0.05$ vs. base line) was significantly less pronounced than 
Table I. Effect of Combined Counterregulatory Hormone Infusion vs. Cortisol Alone on Plasma Amino Acid Concentration ( $\mu$ M)*

\begin{tabular}{|c|c|c|c|c|c|c|}
\hline \multirow[b]{2}{*}{ Amino acid } & \multirow[b]{2}{*}{ Condition } & \multirow[b]{2}{*}{ Control } & \multicolumn{3}{|l|}{ Infusion } & \multirow[b]{2}{*}{ Day 4} \\
\hline & & & Day 1 & Day 2 & Day 3 & \\
\hline \multirow[t]{2}{*}{ Taurine } & Combined & $44 \pm 2$ & $38 \pm 2 \ddagger$ & $40 \pm 2$ & $33 \pm 3 \S$ & $30 \pm 3 \S$ \\
\hline & Cortisol & $48 \pm 4$ & $45 \pm 1$ & $53 \pm 9$ & $41 \pm 3$ & $37 \pm 1$ \\
\hline \multirow[t]{2}{*}{ Threonine } & Combined & $163 \pm 20$ & $74 \pm 12 \S$ & $50 \pm 8 \S$ & $96 \pm 36 \S$ & $136 \pm 24$ \\
\hline & Cortisol & $145 \pm 5$ & $155 \pm 9$ & $172 \pm 11$ & $206 \pm 7 \S$ & $192 \pm 14 \S$ \\
\hline \multirow[t]{2}{*}{ Serine } & Combined & $128 \pm 15$ & $59 \pm 5 \S$ & $54 \pm 8 \S$ & $77 \pm 16 \S$ & $102 \pm 12 \ddagger$ \\
\hline & Cortisol & $97 \pm 10$ & $99 \pm 6$ & $105 \pm 3$ & $102 \pm 2$ & $86 \pm 3$ \\
\hline \multirow[t]{2}{*}{ Glutamine } & Combined & $457 \pm 16$ & $284 \pm 28 \S$ & $309 \pm 37 \S$ & $341 \pm 39 \S$ & $402 \pm 27$ \\
\hline & Cortisol & $503 \pm 20$ & $548 \pm 23$ & $572 \pm 41 \ddagger$ & $559 \pm 27$ & $513 \pm 37$ \\
\hline \multirow[t]{2}{*}{ Glycine } & Combined & $341 \pm 38$ & $177 \pm 16 \S$ & $142 \pm 14 \S$ & $179 \pm 38 \S$ & $248 \pm 28 \S$ \\
\hline & Cortisol & $273 \pm 30$ & $275 \pm 23$ & $274 \pm 26$ & $267 \pm 27$ & $267 \pm 29$ \\
\hline \multirow[t]{2}{*}{ Alanine } & Combined & $284 \pm 28$ & $192 \pm 39$ & $137 \pm 14 \S$ & $199 \pm 39 \ddagger$ & $328 \pm 55$ \\
\hline & Cortisol & $456 \pm 42$ & $523 \pm 45$ & $534 \pm 33$ & $664 \pm 63 \S$ & $524 \pm 50$ \\
\hline \multirow[t]{2}{*}{ Valine } & Combined & $139 \pm 15$ & $81 \pm 13 \S$ & $93 \pm 11 \S$ & $104 \pm 13 \S$ & $131 \pm 16$ \\
\hline & Cortisol & $162 \pm 13$ & $159 \pm 14$ & $165 \pm 17$ & $174 \pm 14$ & $153 \pm 12$ \\
\hline \multirow[t]{2}{*}{ Isoleucine } & Combined & $40 \pm 8$ & $25 \pm 7 \S$ & $34 \pm 7$ & $36 \pm 7$ & $46 \pm 8$ \\
\hline & Cortisol & $39 \pm 4$ & $43 \pm 4$ & $50 \pm 4 \S$ & $61 \pm 3 \S$ & $59 \pm 1 \S$ \\
\hline \multirow[t]{2}{*}{ Leucine } & Combined & $75 \pm 9$ & $38 \pm 9 \S$ & $52 \pm 8 \S$ & $56 \pm 8 \S$ & $76 \pm 13$ \\
\hline & Cortisol & $83 \pm 7$ & $80 \pm 8$ & $85 \pm 8$ & $99 \pm 5 \ddagger$ & $87 \pm 2$ \\
\hline \multirow[t]{2}{*}{ Cystine } & Combined & $100 \pm 10$ & $79 \pm 9 \S$ & $62 \pm 9 \S$ & $75 \pm 15 \S$ & $93 \pm 13$ \\
\hline & Cortisol & $104 \pm 9$ & $107 \pm 5$ & $103 \pm 8$ & $108 \pm 8$ & $105 \pm 5$ \\
\hline \multirow[t]{2}{*}{ Methionine } & Combined & $22 \pm 3$ & $9 \pm 2 \S$ & $10 \pm 4 \S$ & $17 \pm 4 \ddagger$ & $27 \pm 4 \ddagger$ \\
\hline & Cortisol & $24 \pm 3$ & $26 \pm 3$ & $33 \pm 3 \S$ & $38 \pm 4 \S$ & $31 \pm 1 \S$ \\
\hline \multirow[t]{2}{*}{ Tyrosine } & Combined & $47 \pm 6$ & $26 \pm 8 \S$ & $34 \pm 8 \S$ & $39 \pm 8 \ddagger$ & $60 \pm 9 \S$ \\
\hline & Cortisol & $57 \pm 5$ & $40 \pm 2 \ddagger$ & $46 \pm 3$ & $54 \pm 2$ & $54 \pm 1$ \\
\hline \multirow[t]{2}{*}{ Phenylalanine } & Combined & $39 \pm 4$ & $28 \pm 4$ & $44 \pm 4$ & $44 \pm 4$ & $58 \pm 8 \ddagger$ \\
\hline & Cortisol & $52 \pm 2$ & $53 \pm 4$ & $64 \pm 3$ & $66 \pm 4 \ddagger$ & $62 \pm 6$ \\
\hline \multirow[t]{2}{*}{ Total amino acids } & Combined & $1,844 \pm 70$ & $1,090 \pm 93 \S$ & $1,029 \pm 97 \S$ & $1,271 \pm 182 \S$ & $1,713 \pm 120$ \\
\hline & Cortisol & $2,125 \pm 83$ & $2,231 \pm 69$ & $2,351 \pm 52 \ddagger$ & $2,542 \pm 78 \S$ & $2,224 \pm 110$ \\
\hline \multicolumn{7}{|l|}{ Total branched } \\
\hline chain amino & Combined & $254 \pm 31$ & $144 \pm 28 \S$ & $179 \pm 26 \ddagger$ & $197 \pm 26 \ddagger$ & $253 \pm 37$ \\
\hline acids & Cortisol & $284 \pm 23$ & $282 \pm 25$ & $301 \pm 28$ & $333 \pm 21$ & $299 \pm 12$ \\
\hline
\end{tabular}

* Data analyzed using one-way analysis of variance with repeated measures; paired comparisons with control day performed using StudentNeumann-Keuls test. $¥$ Significantly different from control, $P<0.05$. § Significantly different from control, $P<0.01$.

with combined hormone infusion $(P<0.005)$. Plasma insulin levels in the cortisol-infused subjects also tended to be lower during the first $48 \mathrm{~h}$. However, by day 3 , insulin levels in the two groups were virtually identical, despite the significantly ( $P$ $<0.001$ ) higher glucose concentrations in the combined infusion group. Blood beta hydroxybutyrate levels $(0.06 \pm 0.02 \mathrm{mM}$, base line) were not altered by cortisol infusion $(0.07 \pm 0.01$ $\mathrm{mM}$, day 3).
Urinary total nitrogen, urea, and ammonia excretion. Fig. 5 compares the daily urinary nitrogen loss induced by cortisol alone with that observed when multiple hormones were infused. Base-line excretion of total nitrogen $(4.1 \pm 0.7 \mathrm{~g} / 24 \mathrm{~h})$, ureanitrogen $(2.8 \pm 0.5 \mathrm{~g} / 24 \mathrm{~h})$, and ammonia $(0.45 \pm 0.03 \mathrm{~g} / 24 \mathrm{~h}$ ) did not differ from the combined infusion group. During the first $24 \mathrm{~h}$, cortisol alone exerted no demonstrable effect on nitrogen excretion. The early urinary nitrogen response was 
Table II. Effect of Counterregulatory Hormones on 3-Methylhistidine (3-MH) Excretion and Leucine Kinetics

\begin{tabular}{clcccc}
\hline & & & Hormone infusion & \\
\cline { 5 - 6 } & & Control & Day 1 & Day 2 & Day 3 \\
\hline $\begin{array}{c}3-\mathrm{MH} \text { excretion } \\
(\mu \mathrm{mol} / 24 \mathrm{~h})\end{array}$ & Combined & $189 \pm 60$ & $207 \pm 55$ & $233 \pm 66$ & $254 \pm 81^{*}$ \\
{$\left[{ }^{13} \mathrm{C}\right]$ Leucine flux } & Cortisol & $203 \pm 74$ & $217 \pm 74$ & $257 \pm 106$ & $248 \pm 75 \ddagger$ \\
$\left(\mathrm{mmol} / \mathrm{m}^{2}\right.$ per $\left.h\right)$ & Combined & $3.09 \pm 0.23$ & - & - & $3.05 \pm 0.23$ \\
{$\left[{ }^{13} \mathrm{C}\right]$ Leucine oxidation } & Cortisol & $3.11 \pm 0.21$ & - & - & $3.34 \pm 0.27$ \\
$\left(\mathrm{mmol} / \mathrm{m}^{2}\right.$ per $\left.h\right)$ & Combined & $0.369 \pm 0.046$ & - & - & $0.396 \pm 0.055$ \\
\hline
\end{tabular}

* $0.05<P<0.10$ vs. control. $\ddagger P<0.02$ vs. control.

thus significantly reduced $(P<0.05$, day 1$)$ when compared with the combined infusion group. This difference, however, did not persist beyond the first $24 \mathrm{~h}$; by day 3 the cortisolinfused subjects showed augmented rates of excretion of total nitrogen $(7.9 \pm 1.2 \mathrm{~g} / 24 \mathrm{~h}, P<0.02$ vs. base line), urea-nitrogen $(5.0 \pm 1.2 \mathrm{~g} / 24 \mathrm{~h}, P<0.10)$, and ammonia $(1.21 \pm 0.10 \mathrm{~g} / 24 \mathrm{~h}$, $P<0.01$ ), which were comparable with those observed during the combined hormone infusion.

Plasma amino acids (Table I). In contrast to the combined hormone infusion, plasma levels of most amino acids either remained unchanged (taurine, serine, glycine, valine, cystine, and tyrosine) or rose significantly (threonine, $42 \%$; glutamine, $10 \%$; alanine $46 \%$; isoleucine, $56 \%$; leucine, $19 \%$; methionine,
58\%; and phenylalanine, $27 \%$ ) during cortisol infusion. Total plasma amino acids $(2,125 \pm 83 \mu \mathrm{M}$, base line) rose $20 \%$ by day $3(P<0.01)$, reaching levels $(2,542 \pm 78 \mu \mathrm{M})$ that were twofold greater than in the combined hormone group ( $P$ $<0.001)$. In absolute terms, the rise in plasma alanine $(208 \pm 38$ $\mu \mathrm{M})$ exceeded that of any other amino acid, and accounted for $50 \%$ of the total increment in plasma amino acids.

3-Methylhistidine excretion and $\left[1-{ }^{13} \mathrm{C}\right]$ leucine metabolism (Table II). Urinary excretion of 3-methylhistidine gradually increased during cortisol infusion, reaching values on day 3 that were $22 \%$ greater than base line $(P<0.002)$. This response was virtually identical to that observed during combined hormone infusion. Neither leucine flux nor oxidation were

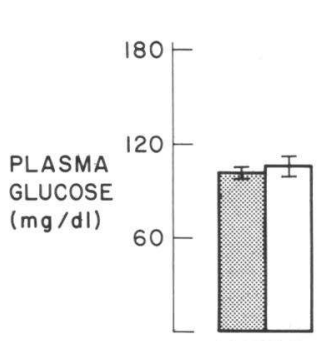

CONTROL

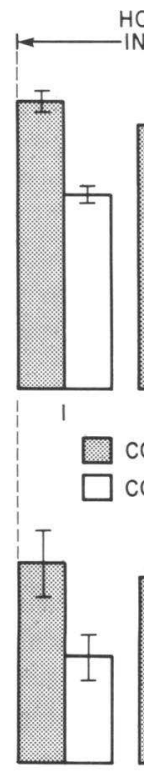

।
HORMONE

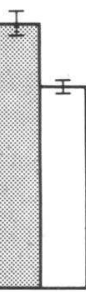

2

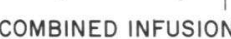

CORTISOL ALONE

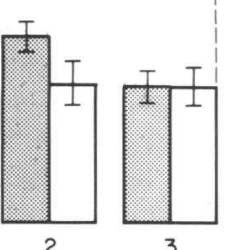

Figure 4. Comparison of the effect of combined hormone infusion and of cortisol alone on plasma glucose and insulin concentrations.

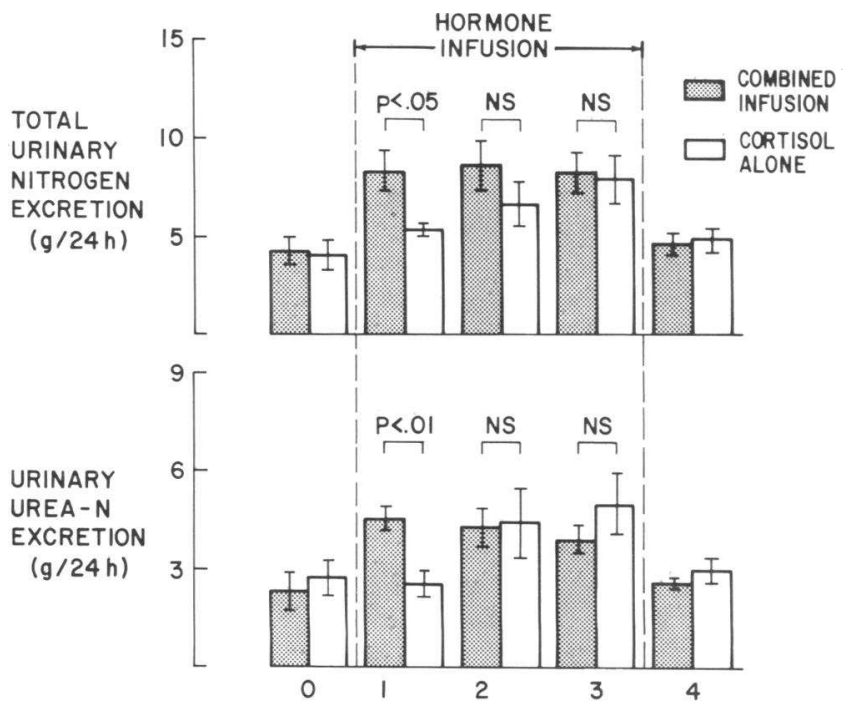

Figure 5. Comparison of nitrogen wasting caused by combined hormone elevations with that caused by cortisol alone. Total nitrogen and urea excretion were only transiently greater in the combined group: by day 3 , daily nitrogen loss was not significantly different between the two conditions. 
significantly altered by cortisol infusion. However, plasma leucine rose significantly (from $83 \pm 7$ to $99 \pm 5 \mu \mathrm{M}, P<0.05$ ); thus, the ratio of whole-body leucine turnover to plasma leucine concentration declined.

\section{Combined hormone infusion without glucose in 3-d fasted subjects}

In fasted subjects combined hormone infusion produced sustained elevations in circulating counterregulatory hormones: plasma concentrations over the 48-h infusion period averaged, for cortisol, $40 \pm 6 \mu \mathrm{g} / \mathrm{dl}$ (base line, 16 \pm 1 ); glucagon, 272 \pm 31 $\mathrm{ng} / \mathrm{ml}$ (base line, 144 \pm 32 ); epinephrine, $230 \pm 30 \mathrm{pg} / \mathrm{ml}$ (base line, $60 \pm 27$ ); and norepinephrine, $673 \pm 44 \mathrm{pg} / \mathrm{ml}$ (base line, $345 \pm 26)$. As expected, preinfusion levels of plasma glucose $(64 \pm 4 \mathrm{mg} / \mathrm{dl})$ and insulin $(10 \pm 2 \mathrm{uU} / \mathrm{ml})$ were significantly lower in these subjects than in those given intravenous glucose $(P<0.01)$. As shown in Table III, plasma glucose doubled during hormone infusion $(P<0.005)$, whereas insulin levels rose only modestly. Both glucose and insulin thus remained significantly lower than in the subjects who received glucose $(P<0.005)$.

The urinary nitrogen response to hormone infusion in these subjects is shown in Table III. Prior to hormone administration the excretion rates of total nitrogen, urea nitrogen, and ammonia were two- to threefold greater than in the subjects who had received carbohydrate for 1 wk. During hormone infusion urinary ammonia rose significantly ( $P$ $<0.02$ ) and returned to base line during the postinfusion period. Although total nitrogen and urea excretion also rose initially, assessment of the magnitude of the response is more difficult because the postinfusion excretion rates were substantially lower than those in the preinfusion period (Table III). If one assumes a linear decline in nitrogen excretion between 3 and $6 \mathrm{~d}$ of starvation (25), the response to hormone infusion

Table III. Metabolic Response to Combined Counterregulatory Hormone Infusion During Total Starvation

\begin{tabular}{lllll}
\hline & \multicolumn{2}{l}{ Day of fast } & \\
\cline { 2 - 4 } & & \multicolumn{3}{c}{ Hormone infusion } \\
\cline { 2 - 4 } & 1 & 2 & 3 & 4 \\
\hline $\begin{array}{c}\text { Plasma glucose } \\
(m g / d l)\end{array}$ & $64 \pm 4$ & $112 \pm 8$ & $126 \pm 1$ & $83 \pm 3$ \\
$\begin{array}{c}\text { Plasma insulin } \\
(\mu U / m l)\end{array}$ & $10 \pm 2$ & $14 \pm 1$ & $17 \pm 4$ & $13 \pm 2$ \\
$\begin{array}{c}\text { Nitrogen excretion } \\
(g / 24 h)\end{array}$ & $14.2 \pm 1.4$ & $17.3 \pm 1.6$ & $14.1 \pm 0.8$ & $8.2 \pm 0.5$ \\
$\begin{array}{c}\text { Urea excretion } \\
(g / 24 h)\end{array}$ & $10.6 \pm 1.1$ & $13.3 \pm 2.6$ & $9.6 \pm 1.1$ & $5.5 \pm 0.4$ \\
$\begin{array}{c}\text { Ammonia excretion } \\
(g / 24 h)\end{array}$ & $1.2 \pm 0.2$ & $2.9 \pm 0.4$ & $3.2 \pm 0.4$ & $1.6 \pm 0.3$ \\
\hline
\end{tabular}

may be roughly estimated by comparing the 48-h hormone infusion period with the sum of the 24-h pre- and postinfusion periods. During hormone infusion, the cumulative excretion of nitrogen and urea totaled $\sim 31 \mathrm{~g} / 48 \mathrm{~h}$ and $23 \mathrm{~g} / 48 \mathrm{~h}$, respectively; in comparison, during the combined pre- and postinfusion periods, total excretion of nitrogen averaged $\sim 22$ $\mathrm{g} / 48 \mathrm{~h}$, and urea $16 \mathrm{~g} / 48 \mathrm{~h}$. Analyzed in this manner, the increments in total nitrogen and urea excretion attributable to hormone infusion averaged roughly 4.5 and $3.5 \mathrm{~g} / 24 \mathrm{~h}$, respectively, values that do not sustantially exceed the daily increments observed in the glucose-infused subjects (see Fig. 3).

\section{Discussion}

The current study was undertaken to determine the extent to which elevated circulating counterregulatory hormones may account for the characteristic metabolic alterations accompanying major injury or illness. By simultaneously infusing cortisol, glucagon, epinephrine, and norepinephrine for $3 \mathrm{~d}$, we reproduced the endocrine milieu of major stress in healthy, unstressed individuals. Comparison of the metabolic changes we observed with those reported in stressed patients reveals some striking similarities, as well as some important differences.

Our data demonstrate that prolonged elevations of multiple counterregulatory hormones cause sustained hyperglycemia with increased endogenous glucose production and total body glucose flux. This finding extends the results of previous shortterm infusion studies (17) by showing that accelerated hepatic glucose production continues for as long as the altered hormonal milieu is maintained. Furthermore, this occurs in the face of concomitant glucose infusion and hyperinsulinemia, each of which are potent inhibitors of hepatic glucose output $(26,27)$. Since patients suffering from major stressful illnesses display quite similar alterations in glucose homeostasis $(4,5,28-30)$, our findings support a primary role for counterregulatory hormones in the genesis of this component of the stress response.

Infusion of cortisol alone caused a significantly smaller rise in plasma glucose, particularly during the first $24 \mathrm{~h}$, when the glucose response in the combined infusion group was maximal (Fig. 4). In keeping with the reduced glycemic response, the early rise in plasma insulin was also less pronounced. However, eventually plasma insulin concentrations in the two groups were comparable, despite the higher glucose levels in the group receiving combined hormone infusion. This observation may reflect suppression of insulin release by catecholamines (31). Such a mechanism may in turn account for the reduced insulin/glucose ratios (reflecting relative inhibition of insulin secretion) that have been reported in patients with trauma (32) and sepsis (29).

Combined counterregulatory hormone infusion was associated with a prompt and sustained increase in urinary nitrogen excretion, indicating accelerated net breakdown of body protein. In contrast, cortisol alone initially had little impact on nitrogen 
loss; however, by the third day, the protein catabolic response was entirely comparable in the two groups (Fig. 5), as were the plasma insulin concentrations. Thus, whereas glucagon and catecholamines exert a potent and sustained hyperglycemic effect in the setting of combined hormone elevation, their effect on nitrogen loss is apparent only in the short term. This early nitrogen loss may reflect the action of both glucagon (33) and epinephrine (34) to acutely stimulate hepatic gluconeogenesis from circulating amino acids. The fall in glucogenic amino acids with combined hormone infusion lends support to this view. These results suggest that in settings characterized by combined counterregulatory hormone elevations (e.g., stress), glucagon and catecholamines may contribute prominently to the early net breakdown of body protein. However, on a more chronic basis, combined elevations of cortisol, glucagon, and catecholamines appear to cause no greater nitrogen wasting than that caused by isolated elevations of cortisol alone.

The failure of combined hormone elevation to persistently augment nitrogen loss is consistent with previous data indicating a relatively modest protein catabolic effect of glucagon and catecholamines. Although high-dose glucagon administration in man has been reported to cause a slight increase in nitrogen output $(13,14)$, other studies have shown no alteration in nitrogen balance during prolonged glucagon infusion (35). Glucagon appears to be devoid of any direct influence on skeletal muscle protein metabolism (36). Similarly, catecholamines are unlikely to play a major protein catabolic role, since they appear to actually inhibit proteolysis and amino acid release from skeletal muscle $(37,38)$. It has been postulated, nevertheless, that catecholamines may exert an indirect protein catabolic effect by inhibiting insulin secretion (7); this, in turn, could potentiate any primary protein catabolic stimulus. However, the current results suggest that the restraining influence of catecholamines on insulin secretion is largely offset by the more marked hyperglycemia associated with multiple hormone elevations. This view is consistent with previous work indicating that hyperglycemia can compensate for the inhibitory effect of catecholamines on beta cell function (39).

Glucocorticoid excess, on the other hand, has long been recognized to cause muscle protein wasting and negative nitrogen balance $(40,41)$. These agents are known to inhibit protein synthesis in skeletal muscle $(42,43)$, and they may also accelerate proteolysis in this tissue $(43,44)$. Nearly $40 \mathrm{yr}$ ago, Ingle et al. (11) demonstrated that adrenalectomized rats replaced with saline alone failed to show the usual increase in urinary nitrogen excretion following skeletal trauma. The current study also supports an important role for hypercortisolism in the protein wasting caused by stress hormones.

The magnitude of nitrogen wasting we observed is very similar to that reported previously in nonobese human volunteers receiving high physiologic doses of synthetic glucocorticoids (45). This suggests that our experimental design did not in some manner exaggerate the effects of cortisol. Conversely, it is unlikely that the effect of combined hormone elevation has been grossly underestimated. Although the compensatory insulin response may have been enhanced by the concurrent glucose infusion, this design was chosen to mimic the clinical setting where hypocaloric glucose is routinely administered. That the glucose infusion did not substantially limit the catabolic response is suggested by the fact that totally fasted subjects showed no greater nitrogen wasting despite a much smaller rise in insulin. The high absolute plasma insulin levels we observed must also be viewed in the context of our subjects' obesity with its attendant insulin resistance; recent evidence supports the concept that obese individuals are resistant to the actions of insulin not only on glucose metabolism, but on amino acid and protein metabolism as well (46). It should further be noted in this context that if expressed in terms of relative rise from base line, the three- to fourfold elevations in insulin observed in this study are in fact very similar to those seen in severely stressed nonobese patients $(5$, 29 ), as well as in nonobese volunteers receiving combined hormone infusion (17). Obesity per se is therefore unlikely to have artificially limited the protein catabolic response to combined hormone elevation. We cannot, however, entirely exclude the possibility that obese individuals may respond to catabolic stimuli differently from the nonobese. Nevertheless, comparison of the protein wasting caused by cortisol vs. combined hormone elevation should in any case be valid since the subjects in these two conditions were equally obese.

Athough the magnitude of nitrogen wasting in the combined and cortisol infusion groups was ultimately comparable, marked differences were observed in the plasma amino acid response (Table I). Combined hormone infusion induced a generalized lowering of plasma amino acids, while cortisol alone caused many amino acids to rise. The contrasting response of plasma leucine is of particular interest. In previous short-term studies, cortisol has been shown to raise, and epinephrine to lower, plasma levels of leucine and other branched chain amino acids $(47,48)$, while glucagon has little, if any, direct effect on these amino acids (49). Insulin also induces a marked reduction in branched chain amino acids (50), and hyperinsulinemia has been shown to enhance the decline in these amino acids caused by epinephrine (51). The present data suggest that when multiple counterregulatory hormones are elevated, the effect of cortisol on plasma leucine may be overcome by the opposing, combined actions of insulin and epinephrine. The kinetic mechanisms underlying the rapid-onset changes in plasma leucine cannot be determined from the turnover measurements performed in the steady state on day 3 . Regardless of the precise mechanisms mediating the amino acid response to hormones, our results underscore the important fact that the plasma amino acid profile bears no simple relationship to overall body nitrogen economy. Indeed, markedly variable amino acid patterns have been reported in patients with major catabolic illnesses (2).

Despite the near-doubling of nitrogen loss caused by hormones, the leucine turnover measurements showed no significant alterations, and thus failed to detect the change in protein kinetics (i.e., synthesis vs. breakdown) that must have occurred to account for the altered net nitrogen balance. One potential explanation for this apparent inconsistency is that the sampling 
compartment for leucine enrichment (plasma) may fail to fully reflect alterations occurring in sequestered tissue sites or intracellular compartments. However, assuming that plasma sampling provides a valid index, the absence of measurable change in leucine kinetics most likely reflects the inability of the turnover technique to detect the very small changes in protein kinetics that can markedly alter nitrogen balance. In the present study basal leucine flux averaged $\sim 3.1 \mathrm{mmol} / \mathrm{m}^{2}$ per $\mathrm{h}$, representing a whole body turnover of $19.5 \mathrm{~g} / \mathrm{d}$ of leucine; taking the contribution of leucine to total body protein as $8 \%$ (52), whole body protein turnover may be estimated as $244 \mathrm{~g} /$ $\mathrm{d}$, or the equivalent of $\sim 39 \mathrm{~g} / \mathrm{d}$ of nitrogen. Thus, the observed increment in nitrogen loss of $\sim 4 \mathrm{~g} / \mathrm{d}$ actually represents only $\sim 10 \%$ of the daily whole body nitrogen flux. Since, for example, a $5 \%$ increase in protein breakdown coupled with a $5 \%$ decrease in synthesis could account for the nitrogen wasting observed, the lack of significant change in leucine kinetics is consistent with the fact that changes of this small magnitude lie near the limits of detection of the technique (18). Although it is possible that with a larger sample size such small changes may have been demonstrable, the current data argue against any gross and sustained alteration in leucine kinetics caused by hormone infusion.

Our results indicate that hormone-mediated nitrogen loss may contribute to the protein dissolution that follows major illness or injury. Nitrogen wasting of the magnitude observed in this study $(\sim 4 \mathrm{~g} / \mathrm{d})$, if sustained for $1 \mathrm{wk}$, would result in the loss of almost a full kilogram of lean body mass. This degree of nitrogen wasting is in the same range as that seen clinically in the uncomplicated postoperative period (53-55). Previous studies have shown that postoperative nitrogen balance is improved when the neuroendocrine response to surgery is inhibited with epidural anesthesia (55). Our data further support the importance of hormonal factors in this setting of mild to moderate stress. However, if one compares the catabolic response we observed with that associated with more severe forms of stress (burns, trauma, and sepsis), several important discrepancies emerge.

The nitrogen loss associated with severe traumatic or thermal injury may be massive (20-40 g/d) (56) and appears to derive in large part from accelerated muscle protein catabolism. Urinary excretion of 3-methylhistidine, an index of muscle protein breakdown, has been shown to be increased by two- to threefold in such settings (57). Studies of whole body protein turnover, using a variety of tracer amino acid techniques, have provided further evidence for a marked augmentation in rates of whole body protein breakdown (58-60). For example, Birkhahn et al. (58) measured leucine kinetics (using $\left[{ }^{14} \mathrm{C}\right]$ leucine) in a group of patients with major skeletal trauma. Compared with healthy volunteers on a similar dietary intake, whole body protein breakdown and leucine flux were increased by $80-85 \%$ and leucine oxidation was accelerated nearly fourfold. Total urinary nitrogen excretion averaged $19 \mathrm{~g} / \mathrm{d}$ in excess of that exhibited by the control subjects.

In contrast with these findings, we observed no significant alterations in leucine flux or oxidation, and only a very modest increase in 3-methylhistidine excretion. Moreover, the net nitrogen wasting caused by counterregulatory hormones $(\sim 4$ $\mathrm{g} / \mathrm{d}$ above base line) was relatively small by comparison. It should further be noted in this context that combined hormone infusion also did not reproduce the marked rise in metabolic rate that characteristically follows major injury and parallels the protein catabolic response (1-4). Although the decline in $T_{3}$ in the present study may have blunted the thermic effect of catecholamines, patients with severe burns or massive injury may simultaneously exhibit profound reductions in $T_{3}$ and $a$ $50-100 \%$ acceleration in resting metabolic rate (61). In previous short-term studies, high-dose catecholamine infusions have also not reproduced increases in oxygen consumption of this magnitude, and, conversely, adrenergic blockade in burn patients has failed to reduce metabolic rates to normal (15).

These considerations suggest that the counterregulatory hormones (glucagon, cortisol, and catecholamines) are not the sole mediators of the marked muscle protein breakdown and hypermetabolism often seen in major injury, burns, or severe sepsis. It is important to note, in contrast, that the glucose response to counterregulatory hormones is at least as great as that commonly seen clinically. This dissociation between the glucose response on the one hand, and the protein and thermic responses on the other, suggests that different regulatory signals may mediate these aspects of the stress response. In the clinical setting, other factors may act in concert with the counterregulatory hormones to orchestrate the full spectrum of the metabolic response to major injury or illness.

\section{Acknowledgments}

The authors gratefully acknowledge the assistance of Mary Walesky, Ralph Jacob, Dr. Rosa Hendler, and the nursing staff of the Yale General Clinical Research Center.

This work was supported in part by National Institutes of Health grants AM-20495, HD-10667, AM-25994, RR-00954, and by the General Clinical Research Center at Yale University (RR-00125).

\section{References}

1. Cuthbertson, D. P. 1979. The metabolic response to injury and its nutritional implications: retrospect and prospect. J. Parenter. Enteral Nutr. 3:108-129.

2. Gelfand, R. A., R. A. DeFronzo, and R. Gusberg. 1983. Metabolic alterations associated with major injury or infection. In New Aspects of Clinical Nutrition. G. Kleinberger and E. Deutsch, editors. Karger, Basel. 211-239.

3. Cuthbertson, D.P. 1932. Observations on the disturbance of metabolism produced by injury to the limbs. $Q$. J. Med. 1:233-246.

4. Wilmore, D. W. 1976. Carbohydrate metabolism in trauma. Clin. Endocrinol. Metab. 5:731-745.

5. Wolfe, R. R., M. S. Durkot, J. R. Allsop, and J. F. Burke. 1979. Glucose metabolism in severely burned patients. Metab. Clin. Exp. 28:1031-1039.

6. Cahill, G. F., Jr. 1970. Starvation in man. N. Engl. J. Med. 282:668-675.

7. Meguid, M. M., M. F. Brennan, T. T. Aoli, W. A. Muller, M. R. Bull, and F. D. Moore. 1974. Hormone-substrate interrelationships following trauma. Arch. Surg. 109:776-783. 
8. Batstone, G. F., K. G. M. M. Alberti, L. Hinks, P. Smythe, J. E. Laing, C. M. Ward, D. W. Ely, and S. R. Bloom. 1976. Metabolic studies following thermal injury. Intermediary metabolites, hormones and tissue oxygenation. Burns. 2:207-225.

9. Marchuk, J. B., R. J. Finley, A. C. Graves, L. I. Wolfe, R. L. Halliday, and J. H. Duff. 1977. Catabolic hormones and substrate patterns in septic patients. J. Surg. Res. 23:177-182.

10. Jaattela, A., A. Alho, V. Avikainen, E. Karahaiju, J. Kataja, M. Lahdensuu, P. Lepisto, P. Rokkanen, and T. Tervo. 1975. Plasma catecholamines in severely injured patients: a prospective study on 45 patients with multiple injuries. Br. J. Surg. 62:177-181.

11. Ingle, D. J., E. O. Ward, and M. H. Kuizenga. 1947. The relationship of the adrenal glands to changes in urinary non-protein nitrogen following multiple fractures in the force-fed rat. Am. J. Physiol. 149:510-515.

12. Alberti, K. G. M. M., G. F. Batstone, K. J. Foster, and D. G. Johnston. 1980. Relative role of various hormones in mediating the metabolic response to injury. J. Parenter. Enteral Nutr. 4:141-145.

13. Marliss, E. B., T. T. Aoli, R. H. Unger, J. S. Soeldner, and G. F. Cahill, Jr. 1970. Glucagon levels and metabolic effects in fasting man. J. Clin. Invest. 49:2256-2270.

14. Wolfe, B. M., J. M. Culebras, T. T. Aoli, N. E. O'Connor, R. J. Finley, A. Kaczowk, and F. D. Moore. 1979. The effects of glucagon on protein metabolism in normal man. Surgery (St. Louis). 86:248-256.

15. Wilmore, D. W., J. M. Long, and A. D. Mason. 1974. Catecholamines: mediators of the hypermetabolic response to thermal injury. Ann. Surg. 180:653-669.

16. Eigler, N., L. Sacca, and R. S. Sherwin. 1979. Synergistic interactions of physiologic increments of glucagon, epinephrine and cortisol in the dog. A model for stress-induced hyperglycemia. J. Clin. Invest. 63:114-123.

17. Shamoon, H., R. Hendler, and R. S. Sherwin. 1981. Synergistic interactions among antiinsulin hormones in the pathogenesis of stress hyperglycemia in humans. J. Clin. Endocrinol. Metab. 52:1235-1241.

18. Matthews, D. E., K. J. Motil, D. K. Rohrbaugh, J. F. Burke, V. R. Young, and D. M. Bier. 1980. Measurement of leucine metabolism in man from a primed, continuous infusion of $\mathrm{L}-\left[1-{ }^{13} \mathrm{C}\right]$ leucine. $\mathrm{Am}$. J. Physiol. 238:E473-E479.

19. DeFronzo, R. A., E. Jacot, E. Jequier, E. Maeder, and J. P. Felber. 1981. The effect of insulin on the disposal of intravenous glucose: results from indirect calorimetry and hepatic and femoral venous catheterization. Diabetes. 30:1000-1007.

20. Passon, P. G., and J. D. Peuler. 1973. A simplified radiometric assay for plasma norepinephrine and epinephrine. Anal. Biochem. 51:618-631.

21. DeMoor, P., O. Steeno, M. Rankin, and A. Hendrikx. 1960. Fluorimetric determination of free plasma 11-hydroxycorticosteroids in man. Acta Endocrinol. 33:297-307.

22. Sacca, L., R. S. Sherwin, R. Hendler, and P. Felig. 1979. Influence of continuous physiologic hyperinsulinemia on glucose kinetics and counterregulatory hormones in normal and diabetic humans. $J$. Clin. Invest. 63:849-857.

23. Novak, N. 1965. Colorimetric ultramicro method for the determination of free fatty acids. J. Lipid Res. 6:431-433.

24. Sherwin, R. S., R. Hendler, and P. Felig. 1975. Effect of ketone infusions on amino acid and nitrogen metabolism in man. J. Clin. Invest. 55:1382-1390.

25. Owen, O. E., P. Felig, A. P. Morgan, J. Wahren, and G. F. Cahill, Jr. 1969. Liver and kidney metabolism during prolonged starvation. J. Clin. Invest. 48:574-583.
26. Felig, P., and J. Wahren. 1971. Influence of endogenous insulin secretion on splanchnic glucose and amino acid metabolism in man. J. Clin. Invest. 50:1702-1711.

27. Sacca, L., R. Hendler, and R. S. Sherwin. 1978. Hyperglycemia inhibits glucose production in man independent of changes in glucoregulatory hormones. J. Clin. Endocrinol. Metab. 47:1160-1163.

28. Long, C. L., J. L. Spencer, J. M. Kinney, and J. W. Geiger. 1971. Carbohydrate metabolism in man: effect of elective operations and major injury. J. Appl. Physiol. 31:102-109.

29. Clowes, G. H. A., H. Martin, S. Walji, E. Hirsch, R. Gazitua, and R. Goodfellow. 1978. Blood insulin responses to blood glucose levels in high output sepsis and septic shock. Am. J. Surg. 135:577582.

30. O'Donnell, T. F., G. H. A. Clowes, G. L. Blackburn, N. T. Ryan, P. N. Benotti, and J. D. B. Miller. 1976. Proteolysis associated with a deficit of peripheral energy fuel substrates in septic man. Surgery (St. Louis). 80:192-200.

31. Porte, D., and R. P. Robertson. 1973. Control of insulin secretion by catecholamines, stress, and the sympathetic nervous system. Fed. Proc. 32:1792.

32. Meguid, M. M., A. Frederico, and J. S. Soeldner. 1978. Temporal characteristics of insulin:glucose ratio after varying degrees of stress and trauma in man. J. Surg. Res. 25:389-393.

33. Cherrington, A. D., P. E. Williams, G. Shulman, and W. W. Lacy. 1981. Differential time course of glucagon's effect on glycogenolysis and gluconeogenesis in the conscious dog. Diabetes. 30:180-187.

34. Sacca, L., C. Vigorito, M. Cicalo, G. Corso, and R. S. Sherwin. 1983. Role of gluconeogenesis in epinephrine-stimulated hepatic glucose production in humans. Am. J. Physiol. 245:E294-E302.

35. Sherwin, R. S., R. Hendler, and P. Felig. 1977. Influence of physiologic hyperglucagonemia on urinary glucose, nitrogen, and electrolyte excretion in diabetes. Metab. Clin. Exp. 26:53-58.

36. Pozefsky, T., R. G. Tancredi, R. T. Moxley, J. Dupre, and J. D. Tobin. 1976. Metabolism of forearm tissues in man: studies with glucagon. Diabetes. 25:128-135.

37. Garber, A. J., I. E. Karl, and K. M. Kipnis. 1976. Alanine and glutamine synthesis and release from skeletal muscle. IV. Beta-adrenergic inhibition of amino acid release. J. Biol. Chem. 251:851-857.

38. Li, J. B., and L. S. Jefferson. 1977. Effect of isoproterenol on amino acid levels and protein turnover in skeletal muscle. Am. $J$. Physiol. 234:E243-E249.

39. Beard, J. C., C. Weinberg, M. A. Pfeifer, J. D. Best, J. B. Halter, and D. Porte, Jr. 1982. Interaction of glucose and epinephrine in the regulation of insulin secretion. Diabetes. 31:802-807.

40. Long, C. N. H., B. Katzin, and E. G. Fry. 1940. The adrenal cortex and carbohydrate metabolism. Endocrinology. 26:309-344.

41. Goldberg, A. L., and H. M. Goodman. 1969. Relationship between cortisone and muscle work in determining muscle size. $J$. Physiol. (Lond.). 200:667-675.

42. Wool, I. G., and E. I. Weinshalbaum. 1959. Incorporation of ${ }^{14} \mathrm{C}$-amino aids into protein of isolated diaphragms: role of the adrenal steroids. Am. J. Physiol. 197:1089-1092.

43. Goldberg, A. C. 1969. Protein turnover in skeletal muscle. II. Effects of denervation and cortisone on protein catabolism in skeletal muscle. J. Biol. Chem. 244:3223-3229.

44. Tomas, F. M., H. N. Munro, and V. R. Young. 1979. Effect of glucocorticoid administration on the rate of muscle protein breakdown in vivo in rats, as measured by urinary excretion of $N$-methylhistidine. Biochem. J. 178:139-146.

45. Sapir, D. G., T. Pozefsky, J. P. Knochel, and M. Walser. 1977. 
The role of alanine and glutamine in steroid-induced nitrogen wasting in man. Clin. Sci. Mol. Med. 53:215-220.

46. Forlani, G., P. Vannini, G. Marchesini, M. Zoli, A. Ciavarella, and E. Pisi. 1984. Insulin-dependent metabolism of branched chain amino acids in obesity. Metab. Clin. Exp. 33:147-150.

47. Shamoon, H., Jacob, R., and R. S. Sherwin. 1980. Epinephrineinduced hypoaminoacidemia in normal and diabetic human subjects: effect of beta blockade. Diabetes. 29:875-881.

48. Gelfand, R. A., R. Jacob, H. Shamoon, and R. S. Sherwin. 1984. Stress hormone-insulin interactions: effects on plasma amino acids. J. Parenter. Enteral Nutr. 8:89.

49. Liljenquist, J. E., S. B. Lewis, A. D. Cherrington, B. C. SinclairSmith, and W. W. Lacy. 1981. Effects of pharmacologic hyperglucagonemia on plasma amino acid concentrations in normal and diabetic man. Metab. Clin. Exp. 30:1195-1199.

50. Felig, P., E. Marliss, and G. F. Cahill, Jr. 1969. Plasma amino acid levels and insulin secretion in obesity. $N$. Engl. J. Med. 281:811816.

51. DeFronzo, R. A., H. Shamoon, and R. Sherwin. 1980. Epinephrine-induced hypoaminoacidemia - a beta-adrenergic effect. Clin. Res. 28:258A. (Abstr.)

52. Waterlow, J. C., P. J. Garlick, and D. J. Millward. 1978. In Protein Turnover in Mammalian Tissues and in the Whole Body. Elseiver/North Holland Publishing Company, New York. 804 pp.

53. Hoover, H. C., J. P. Grant, C. Gorschboth, and A. S. Ketcham. 1975. Nitrogen-sparing intravenous fluids in postoperative patients. $N$. Engl. J. Med. 293:172-175.

54. Craig, R. P., H. A. Davidson, D. Tweedle, and I. D. A.
Johnston. 1977. Intravenous glucose, amino acids, and fat in the postoperative period. Lancet. II:8-11.

55. Brandt, M. R., A. Fernandes, and R. Mordhorst. 1978. Epidural analgesia improves postoperative nitrogen balance. Br. Med. J. 1:11061108.

56. Kinney, J. M., and P. Felig. 1979. The metabolic response to injury and infection. In Endocrinology. L. J. DeGroot, G. F. Cahill, Jr., L. Martini, D. H. Nelson, W. D. Odell, J. T. Potts, Jr., E. Steinberger, and A. I. Winegrad, editors. Grune \& Stratton, New York. 1963-1985.

57. Long, C. L., R. H. Birkhahn, J. W. Geiger, J. E. Beets, W. R. Schiller, and W. S. Blakemore. 1981. Urinary excretion of 3-methylhistidine: an assessment of muscle protein catabolism in normal adult subjects and during malnutrition, sepsis, and skeletal trauma. Metab. Clin. Exp. 30:765-776.

58. Birkhahn, R., C. L. Long, D. Fitkin, J. W. Geiger, and W. D. Blakemore. 1980. Effects of major skeletal trauma on whole body protein turnover in man measured by $\mathrm{L}-\left(1,{ }^{14} \mathrm{C}\right)$-leucine. Surgery (St. Louis). 88:294-300.

59. Kien, C. L., V. R. Young, D. K. Rohrbaugh, and J. F. Burke. 1978. Increased rates of whole body protein synthesis and breakdown in children recovering from burns. Ann. Surg. 187:383-391.

60. Long, C. L., M. Jeevanandam, B. M. Kim, and J. M. Kinney. 1977. Whole body protein synthesis and catabolism in septic man Am. J. Clin. Nutr. 30:1340-1344.

61. Becker, R. A., G. M. Baughan, M. G. Ziegler, B. A. Pruitt, and A. D. Mason. 1982. A randomized prospective study of triiodothyronine replacement in hypermetabolic, chemically hypothyroid burn patients. The Endocrine Society Annual Meeting. (Abstr. 558). 